\title{
FUNCTIONAL RESPONSE OF THE COCCINELLID PREDATOR Stethorus gilvifrons MULSANT FEEDING ON THE TWO SPOTTED SPIDER MITE, Tetranychus urticae KOCH: THE EFFECT OF DIFFERENT PREY STAGES \\ Osman, M. A. \\ Agriculture Zoology Dept., Fac. Agric., Mansoura Univ., Mansoura 35516, Egypt. \\ E- mail: - mesoma20@mans.edu.eg
}

\begin{abstract}
The functional response of a ladybeetle, Stethorus gilvifrons Mulsant, to increasing density of two spotted spider mite, Tetranychus urticae koch, was of the curvilinear shape depicting Holling's type II response with larval stage being the most voracious stage when compared with nymphal and adult stages. Results of the maximum likelihood analyses confirmed this type. By plotting a type II functional response model and polynomial logistic regression model to the numbers and proportions of consumed stages of $T$. urticae, respectively, the resulting regression lines fitted the data well. A sensitivity analysis of the functional response model shows the crucial effect of prey stages on predation rates by $S$. gilvifrons. Theoretically, based on the lowest handling time for $S$. gilvifrons on larval stage of $T$. urticae, the maximum numbers of mites that could be consumed by a single female of $S$. gilvifrons within $24 \mathrm{~h}$ period were 77. 42 larvae. Based on the inversely density-dependent predation rate for $S$. gilvifrons on different prey stages, it seems to be more effective in low prey densities and this result has to be considered in future inundative biological control programs. These results might be a better strategy for developing mass rearing of $S$. gilvifrons and biocontrol program of $T$. urticae.
\end{abstract}

\section{INTRODUCTION}

Approximately 90 worldwide species of the tribe Stethorini Dobzhansky (genera: Stethorus Weise and Parasthethorus Pangand Mao) are the only specialist mite predators in the Coccinellidae. Various species of Stethorini have received considerable attention over the last five decades because of their potential as biological control agents of spider mites. At least 12 species of Stethorini have been imported into the US for this purpose (Gordon, 1985) and many more have been purposefully redistributed throughout the world. Chazeau (1985) summarized information on Stethorini general biology and reported that $40 \%$ of the 68 species attacked spider mites of economic importance.

Stethorus gilvifrons Mulsant (Coleoptera: Coccinellidae) is a biological control agent of the two spotted spider mite, Tetranychus urticae Koch (Acari: Tetranychidae), which is a serious pest of different crops and ornamental plants over the world (Takafuji et al., 2000; Sim et al., 2003; Zhang, 3003; Alatawi et al., 2005). It feeds voraciously on different growth stages of spider mites (Tetranchidae) and the closely related Tenuipalpididae, which are known as false spider mites or flat mites (Chazeau, 1985; Ahmed and Ahmed, 1988; Afshari, 1999). 
Prior to the release of natural enemy in a biological control program, it is essential to evaluate its efficiency under laboratory conditions. One informative method for assessing the efficiency of natural enemies is the study of their foraging behavior including functional response (Fathipour et al. 2006; Bayoumy 2009). Functional response is the number of preys successfully consumed per predator as a function of prey density (Solomon 1949). It is a commonly measured attribute of natural enemies. Practitioners of inundative biological control may use functional response to estimate the appropriate numbers of bio-control agents to be released in order to bring about an immediate reduction in pest numbers (Mills and Lacan 2004). Holling (1965) proposed three types of functional responses: type I, a linear rise to a plateau; type II, a curvilinear rise to a plateau; and type III, a sigmoid curve rising to a plateau which then levels off under the influence of handling time or satiation (Hassell 2000). Among the types of functional responses, type II and III have received the most attention (Allahyari et al. 2004).

Many early studies of various species of Stethorini concluded that they are "high density predators" unable to regulate spider mite populations at low densities (Fleschner, 1950; Bailey and Caon, 1986; Tanigoshi and McMurtry, 1977). Congdon et al. (1993) challenged this "high density predator" designation and asserted that high density spider mite populations have become common only since the advent of synthetic insecticides (Huffaker et al., 1970). Although some bionomic studies on S. gilvifrons have been conducted by Haji-Zadeh et al. (1993) and Afshari (1999), no detailed study has reported on the influence of $T$. urticae stages on its functional responses. Only Sohrabi and Shishehbor (2007) reported a type III response of $S$. gilvifrons on Tetranychus turkestani Ugarov and Nikolski. Therefore, the objective of this study is to quantify the effect of prey stage densities on consumption rate of $S$. gilvifrons for improving our understanding of preypredator interaction and to know some information about the prey stage which could be maximizing mass rearing program for this predator. Thus, this study might lead to develop a better strategy for mass rearing of $S$. gilvifrons and biological control of $T$. urticae.

\section{MATERIALS AND METHODS}

\section{Stock culture of Tetranchyus urticae and Stethorus gilvifrons}

The two spotted spider mite $T$. urticae, used as prey for the coccinellid predator S. gilvifrons, was reared on the whole plants of potted beans, Phaseolus vulgaris $\mathrm{L}$. at room conditions of $26 \pm 3,65 \pm 10 \% \mathrm{rh}$, and $16: 8$ (L:D) photoperiod. The initial population of $S$. gilvifrons was originated from castor plants (Ricinus communis L.) in the pupal stage at Mansoura district, Egypt. The collected pupae were kept in Eppendorf tubes and maintained in the incubator at $25 \pm 1$ and 16:8 (L:D) photoperiod until adult emergence. The stock culture of $S$. gilvifrons was then started using all stages of $T$. urticae on caster leaves. One leaf disc placed upside-down on water saturated cotton (2 $\mathrm{cm}$ thick) in a plastic box $(20 \times 10 \times 5 \mathrm{~cm})$. Water was added daily to cover the base of the box to prevent the mites from escaping. A surplus of all stages of 
T. urticae was brushed daily onto the leaf arenas using a soft brush and funnel. The stock culture was maintained in the incubator at $25 \pm 1{ }^{\circ} \mathrm{C}, 65 \pm$ 10\% RH., and 16:8 (L:D) photoperiod. The leaf discs were renewed once a week. The predatory mites used in the experiment were reared for two successive generations prior to this study (i.e., functional response).

\section{General experimental conditions}

Functional response test was carried out into the modified Huffaker cell (Sabelis, 1981 and Overneer, 1985) provided with caster leaf disc as an experimental arena. The tested densities of $T$. urticae for S. gilvifrons were transferred from potted bean leaves to caster leaf disc using a soft brush. The functional response test was conducted at $25 \pm 1{ }^{\circ} \mathrm{C}, 65 \pm 10 \% \mathrm{RH}$ and $16: 8$ $(\mathrm{L}: D)$ photoperiod. Three days old females of $S$. gilvifrons were used in the current test. Prior to the functional response test, the predators were collected from the stock culture in their pupal stage and places in Petri dishes. The emerged adults were provided with $T$. urticae as a source for food for $48 \mathrm{~h}$, then separated individually in Eppendorf tubes and starved for another $24 \mathrm{~h}$ before being used in the experiment to standardize their hunger.

\section{Functional response}

In order to test the response of $S$. gilvifrons to change in the prey stage density of the two spotted spider mite, individual predators $(72 \mathrm{~h}$ old $)$ were exposed to ten prey density levels (viz., 10, 20, 30, 40, 50, 60, 70, 80, 90,100 ) of each tested stage (i.e., larva, nymph and adult) for $24 \mathrm{~h}$. In case of adult mite females, newly females were transferred directly from the stock culture to the experimental arena to avoid reproduction of ovipositing females in the experimental arena. Fifteen replications of each prey density were set up simultaneously. After $24 \mathrm{~h}$, the predators removed from the experimental arenas and the live mites left in the experimental arena were counted to determine the number of aphids consumed.. Only replicates with the predator surviving after $24 \mathrm{~h}$ exposure time were considered.

\section{Data analysis}

Data from functional response experiments were used to establish the type and parameters of functional response using the approach developed by Juliano (2001). This approach includes two sequential analyses. Initially, the shape (type) of functional response must be determined, typically by determining if the data fit a type II or III functional response. A polynomial logistic regression of the proportion of attacked preys $\left(\mathrm{N}_{\mathrm{a}} / \mathrm{N}_{0}\right)$ vs. the initial number of prey offered $\left(\mathrm{N}_{0}\right)$ is established for distinguishing between both types. The curves of $N_{a} / N_{0}$ vs. $N_{0}$ when the response is a type II, have the shape of a negative exponential (proportion of attacked preys decaying exponentially) and when the response is a type III have a dome-shape, with a maximal of proportion attacked and then a continuous decline. These curves may both be fit by quadratic (or higher order) polynomials expressions. In the type II curve, the linear $\left(P_{1}\right.$ in Eq. 1$)$ and quadratic $\left(P_{2}\right.$ in Eq. 1$)$ term would be negative (initially decreasing) whereas in the type III curve the linear term would be positive (initially increasing) and the quadratic term negative (Trexler et al., 1988; Juliano, 2001). Thus, one criterion for separating type I to III functional responses is to analyze the proportion of prey attacked and to test for significant positive or negative linear coefficients from Eq. 1. Linear 


\section{Osman, M. A.}

term not significantly different from 0 indicates a type I functional response, a significant negative indicates a type II response, and a significant positive indicates a type III (Juliano 1993). The second part of the analyses uses a non-linear least squares method to obtain estimates of the functional response parameters (Juliano, 2001).

Relationship between proportion of prey attacked and density of prey offered were used, initially, to perform logistic regression using the polynomial function:

$$
\frac{N_{a}}{N_{0}}=\frac{\exp \left(P_{0}+P_{1} N_{0}+P_{2} N_{0}{ }^{2}+P_{3} N_{0}{ }^{3}\right)}{1+\exp \left(P_{0}+P_{1} N_{0}+P_{2} N_{0}{ }^{2}+P_{3} N_{0}{ }^{3}\right)}
$$

where $\mathrm{N}_{\mathrm{a}}$ is the number of prey attacked, $\mathrm{N}_{0}$ is the initial prey density, and the parameters $P_{0}, P_{1}, P_{2}$, and $P_{3}$ are the constant, linear, quadratic, and cubic parameters, respectively, related to the slope of the curve. Maximum likelihood estimates of parameters $\mathrm{P}_{0}$ to $\mathrm{P}_{3}$ were obtained by applying logistic regression (CATMOD procedure in SAS software) (SAS, 2003) to a dichotomous variable that equaled 0 for surviving preys and 1 for attacked preys. As in many cases a cubic or higher order expression are necessaries for good fits.

Once the functional response type was determined from logistic regression analyses and log likelihood-ratio tests, iterative non-linear least squares regression (NLIN procedure with Proc method of SAS) (SAS, 2003) was used to estimate the parameters of Holling's disc equation (Eq. 2) (Holling, 1959).

$$
\mathrm{N}_{\mathrm{a}}=\mathrm{a} T \mathrm{~N}_{0} / 1+\mathrm{a} \mathrm{T}_{\mathrm{h}} \mathrm{N}_{0}
$$

where $\mathrm{T}$ is the time of exposure (24 h), a is the rate of successful attack, and $T_{h}$ is the handling time.

Values of $T_{h}$, estimated by non-linear least squares regression, were used to calculate maximum attack rate as $T / T_{h}$ (Hassel, 2000), that represent the maximal number of preys that could be consumed by a predator of $\mathrm{S}$. gilvifrons during $24 \mathrm{~h}$.

\section{RESULTS}

Prey consumption by S. gilvifrons increased from 10 to 60,10 to 55.93 , and 10 to 35.73 individuals with increase in density of larvae, nymphs, and adults of $T$. urticae from 10 to 60,10 to 60 , and 10 to 50 , respectively. In contrast, the proportion of killed preys by $S$. gilvifrons decreased from 1 to $0.43,1$ to 0.28 , and 1 to 0.13 with increase in density of larvae, nymphs, and adults of $T$. urticae from 10 to 100 , respectively. The increase in prey consumption and the decrease in proportion of consumed preys by the above predator with increased densities of prey stages were curvilinear in shape (fig. 1). 

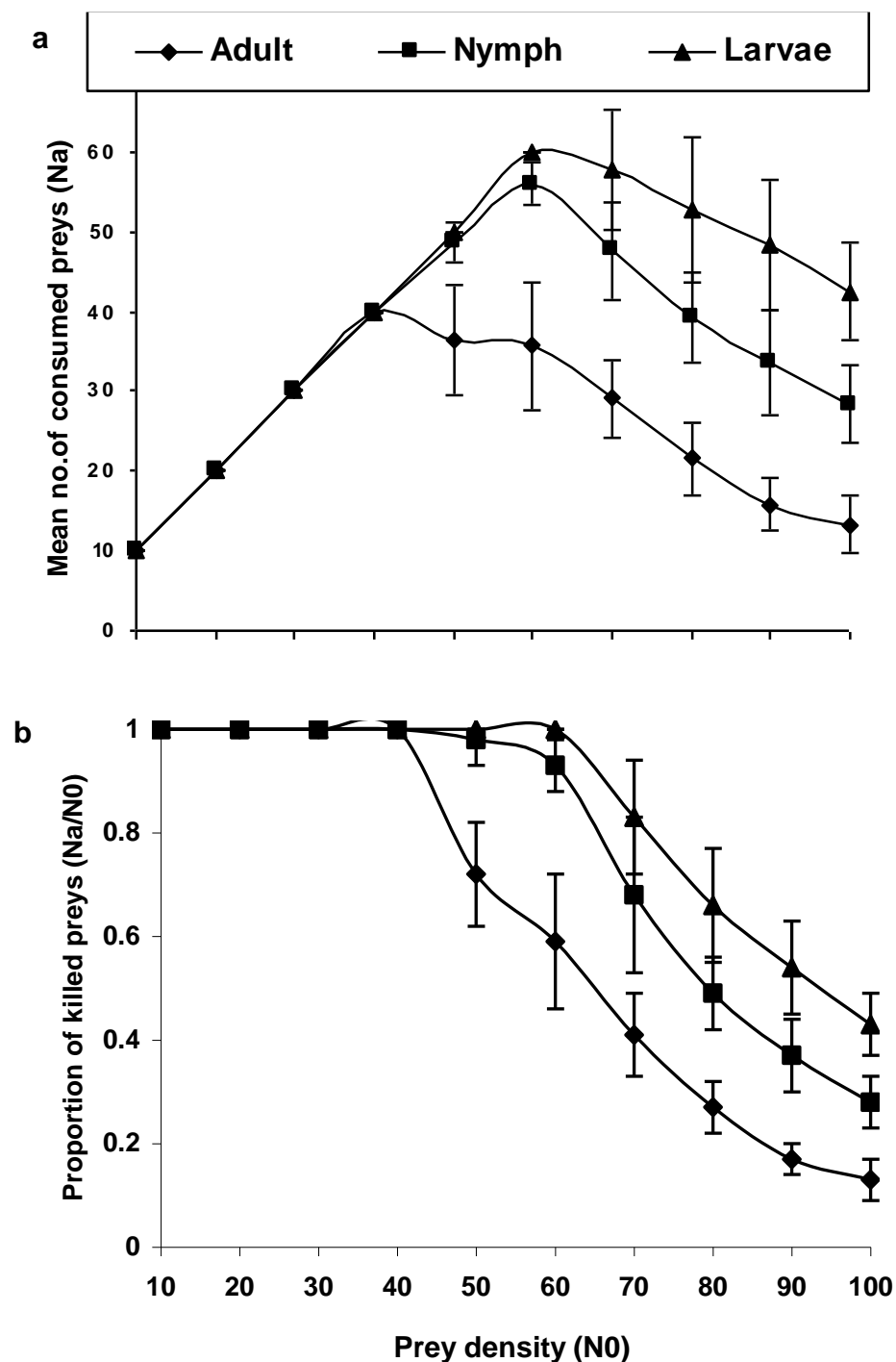

Fig. 1: Mean numbers (a) and proportions (b) of different stages of $T$. urticae consumed by a single female of $S$. gilvifrons $\left(\mathrm{N}_{\mathrm{a}} / \mathrm{P}\right)$ in relation to different prey densities $\left(\mathrm{N}_{0} / \mathrm{P}\right)$ determined in the experiments.

The accelerated decrease in the proportion of consumed stages of $T$. urticae in relation to their density best-fitted the description of a type II functional response. Results of the maximum likelihood analyses confirmed this observation (Table 1). 
Osman, M. A.

Table 1: Maximum likelihood estimates from logistic regression of the proportion of different stages of $T$. urticae consumed by $S$. gilvifrons as a function of initial prey density.

\begin{tabular}{cccccc}
\hline Prey stages & Parameter & Estimate & SE & $\begin{array}{c}\text { Chi- } \\
\text { Square }\left(\mathbf{X}^{2}\right)\end{array}$ & P-value \\
& Intercept & 131.2 & 17.23 & 58.01 & $<0.0001$ \\
\multirow{4}{*}{ Larval } & Linear $\left(\mathrm{N}_{0}\right)$ & -4.426 & 0.62 & 50.44 & $<0.0001$ \\
& Quadratic $\left(\mathrm{N}_{02}\right)$ & 0.0501 & 0.0075 & 45.24 & 0.002 \\
& Cubic $\left(\mathrm{N}_{03}\right)$ & -0.00019 & 0.000029 & 41.67 & 0.02 \\
& Intercept & 31.2786 & 5.6602 & 30.54 & $<0.0001$ \\
\multirow{4}{*}{ Nymphal } & Linear $\left(\mathrm{N}_{0}\right)$ & -0.8991 & 0.2203 & 16.65 & $<0.0001$ \\
& Quadratic $\left(\mathrm{N}_{02}\right)$ & 0.00865 & 0.00282 & 9.43 & 0.002 \\
& Cubic $\left(\mathrm{N}_{03}\right)$ & -0.00003 & 0.000012 & 5.92 & 0.02 \\
& Intercept & 21.6752 & 2.1967 & 97.36 & $<0.0001$ \\
& Linear $\left(\mathrm{N}_{0}\right)$ & -0.7456 & 0.0952 & 61.36 & $<0.0001$ \\
& Quadratic $\left(\mathrm{N}_{02}\right)$ & 0.00856 & 0.00134 & 40.86 & $<0.0001$ \\
& Cubic $\left(\mathrm{N}_{03}\right)$ & -0.00003 & 0.000006 & 32.15 & $<0.0001$ \\
\hline
\end{tabular}

A significant negative estimate for the parameter $N_{0}$ indicates that the slope of the functional response curve is declining, thus a type II functional response

For S. gilvifrons consuming different stages of $T$. urticae, the significantly negative parameters of $N_{0}$ suggested that the slopes of the functional response curves were declining, which is characteristics of a type II functional response. By plotting a type II functional response model and polynomial logistic regression model to the number and proportions of consumed stages of $T$. urticae, respectively, the resulting regression lines fitted the data well (fig. 2).

The highest instantaneous rate of attack (a) and the lowest handling time $\left(T_{h}\right)$ for $S$. gilvifrons were correlated with adult and larval stages of $T$. urticae, respectively (Table 2 ).

Table 2: Parameter estimates (95\% confidence interval) of the attack constant [a $\left.\left(h^{-1}\right)\right]$, handling time [ $\left.T_{h}(h)\right]$, and maximum number of killed preys $\left(T / T_{h}\right)$ for Stethorus gilvifrons females preying different stages of Tetranychus urticae derived from Holling $s$ disc equation.

\begin{tabular}{|c|c|c|c|c|c|c|c|}
\hline \multirow{2}{*}{$\begin{array}{c}\text { Prey } \\
\text { stages }\end{array}$} & \multirow[t]{2}{*}{ a } & \multicolumn{2}{|c|}{$\begin{array}{c}\text { Asymptotic } 95 \% \\
\mathrm{Cl}\end{array}$} & \multirow[t]{2}{*}{$T_{h}$} & \multicolumn{2}{|c|}{$\begin{array}{c}\text { Asymptotic } \\
95 \% \mathrm{Cl}\end{array}$} & \multirow[t]{2}{*}{$T / T_{h}$} \\
\hline & & lower & upper & & lower & upper & \\
\hline Larval & $0.08 \pm 0.008$ & 0.0673 & 0.1003 & $0.31 \pm 0.02$ & 0.2752 & 0.3528 & 77.42 \\
\hline Nymphal & $0.11 \pm 0.02$ & 0.0753 & 0.1493 & $0.46 \pm 0.03$ & 0.4050 & 0.5182 & 52.17 \\
\hline Adult & $0.214 \pm 0.09$ & 0.0432 & 0.3843 & $0.83 \pm 0.05$ & 0.7250 & 0.9264 & 28.92 \\
\hline
\end{tabular}

Theoretically, based on the lowest handling time for S. gilvifrons on larval stage of $T$. urticae, the maximum numbers of $T$. urticae that could be consumed by a single female of $S$. gilvifrons within $24 \mathrm{~h}$ period were 77.42 larvae $\left(24 \mathrm{~h} / \mathrm{T}_{\mathrm{h}}\right)$. 

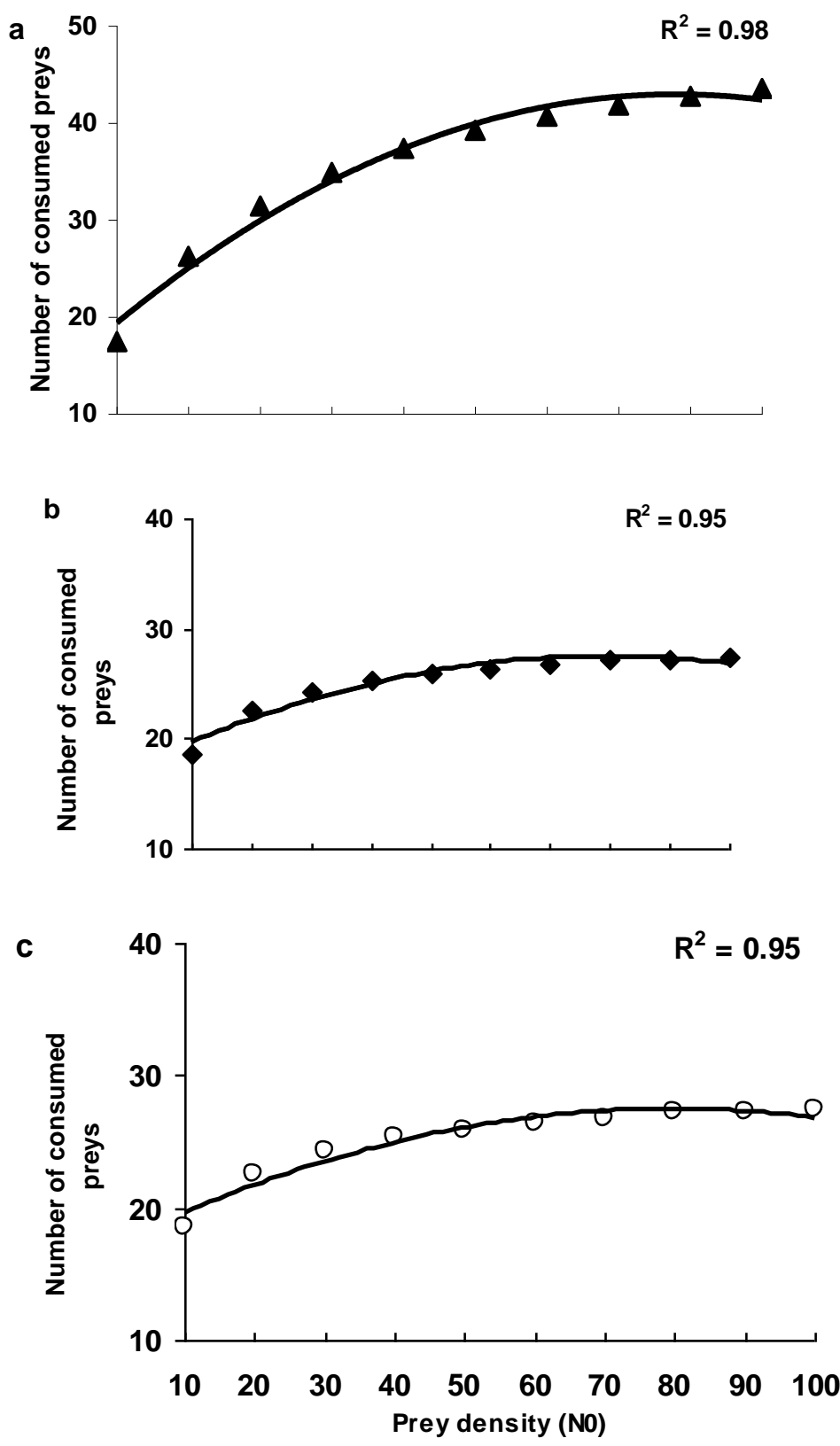

Fig. 2: Functional response of $S$. gilvifrons to different densities $\left(\mathrm{N}_{0} / \mathrm{P}\right)$ of $T$. urticae (a: larva; b: nymphal I; c: adult stage) predicated by the Holling's model. The lines represent the best-fitted type II functional response curves of the predator feeding on larval, nymphal and adult stages $\left(r^{2}=0.95,0.98\right.$, and 0.95 , respectively). 


\section{DISCUSSIONS}

The exactness of functional response as a comparison tool in above mentioned fields is highly related to models and data analysis; the use of inappropriate models and methods of analysis may result in an incorrect estimation. The response of $S$. gilvifrons to stages was characterized by a reduction in the proportion of prey consumed with increasing prey density, reaching a minimum consumption of ca. $0.43,0.28$, and 0.13 for larvae, nymphs, and adults of $T$. urticae at the highest prey density (100 T. urticae). Decreasing in proportion of prey consumed with increasing prey density is common for arthropods predator as a result of satiation level and handling time required for each prey item consumed (Holling, 1961).

For each density, predation by $S$. gilvifrons varied between the stages of $T$. urticae. At density of $10,20,30$, and $40 \mathrm{~T}$. urticae, all individuals were consumed, which suggests that prey density was below the level necessary for survival. At prey density of 50 , the proportion of prey consumed was 0.82 and 0.98 , and 0.73 on the larvae, nymphs, and adults of $T$. urticae, respectively. Each adult female may consume 30-60 mites per day for Stethorus madecassus Chazeau (Chazeau, 1974a), S. punctum (LeConte) (Tanigoshi and McMurtry, 1977), S. punctillum Weise (Roy et al., 2003), S. japonicus Kamiya (Mori et al., 2005), and S. tridens Gordon (Fiaboe et al., 2007). According to Houck (1991), the feeding behaviour of Stethorus varies with prey density and the obtained results found agreed with this statement. At higher prey densities, the predators spend less time searching the prey resulting in higher prey consumption than in lower densities but predators require time to attack the prey.

The type of functional response and estimated parameters for a natural enemy could be affected by some factors such as host plant. Temperature and type of prey or host and prey stages (Eveleigh and Chant, 1981; Coll and Ridgway, 1995; Nwilene and Nachman, 1996; Wang and Ferro, 1998; De Clercq et al., 2000; Mohaghegh et al., 2001). Although the type of functional response for $S$. gilvifrons did not alter among the different stages of $T$. urticae in this study, the effects of these factors are reflected in the values of the attack rate and the handling time.

Although the logistic regression determined the shape of the functional responses of $S$. gilvifrons to be a type II response and significant models could be fitted, the parameter estimates of these functional responses were not always significantly different from zero. The lack of significant parameters complicates ecological interpretation of the estimated functional responses. According to Juliano (2003) the best guide to distinguish between the type II and type III response is to observe the shape of the fitted curve. In the current study, the shapes of the type II functional response models fitted the data very well. In all type II response models a plateau appears to be reached at the higher prey densities. However, the number of prey consumed at this plateau was quite low. This low predation rate may be related to the long handling times. 
A type II functional response is the most common type reported for most coccinellid predators (Isikber, 2005). The significant negative values for the linear parameter obtained in this study confirm the type II response for $S$. gilvifrons on all tested prey stages. The obtained, type Il functional response for S. gilvifrons was similarly reported for Stethorus vagans (Blackburn) (Ullah, 2000), S. punctum (Hull et al., 1977), S. japonicus (Gotoh et al., 2004), and S. tridens (Britto et al., 2009), all preying on T. urticae..

Although Holling's disc equation (1959) is widely used to estimate parameters of type II functional response, some authors emphasize on the limitation of Holling's disc equation, and suggest Roger's random predator equation (1972) as an alternative, which is more appropriate when reencounter (for a parasitoid) or prey depletion (for a predator) may be occurs during the experiment (Juliano, 2001). Holling's disc equation can be used only when Roger's model does not enable the researcher to estimate valid parameters ( $b$ and $T_{h}$ ). For example, Mohaghegh et al. (2001) used Holling's model because Rogers's model provides invalid parameters for their data set. Similarly, Holling's model provided valid parameters for our data set. We first used the Roger's random equation but the parameters estimated using this model were theoretically unappreciated $\left(b\right.$ and $T_{h}$ were overestimated).

Handling time of $S$. gilvifrons estimated in this study on $T$. urticae larvae $(0.31 \mathrm{~h})$ is shorter than that of 0.46 and $0.83 \mathrm{~h}$ on $T$. urticae nymphs and adults. However, the highest attack rate for S. gilvifrons was found on $T$. urticae adults. This may be due to $S$. gilvifrons at high prey densities continued to feed even when satiated and continued to attack mites, initiate feeding, but then subsequently abandon the prey with minimal attack of bodily parts. However, it takes a long time in dealing with each adult individual of prey. This may be due to the bigger size and faster movement of prey adult than other immature stages. The ratio between exposure time and handling time $\left(T / T_{h}\right)$ is an indicator of maximum predation. Based on the lowest handling time for $S$. gilvifrons on larval stage of $T$. urticae the maximum number of consumed preys (per day) by S. gilvifrons is 77.42 larvae of $T$. urticae. The handling time and the maximal number of consumed preys $\left(T / T_{h}\right)$ of $T$. urticae nymphs by $S$. gilvifrons in our study is similar to that reported for the same predator on T. turkestani nymphs (Sohrabi and Shishehbor, 2007).

According to Berry et al. (1988) several problems are associated with estimating functional responses in the laboratory. Predators are not allowed to leave a patch in search of higher densities where prey location is more efficient, and as a consequence predators consume more prey at low density than they would probably do in nature (Van Lenteren and Bakker, 1976). Moreover, the length of the experimental period may be critical (Eveleigh and Chant, 1981). Such studies are, however, useful in providing the first step to compare the efficiency of a natural enemy against different prey species or stages and to provide a valid means of comparing host finding abilities of candidate natural enemies (Munyaneza and Obrycki, 1997)

Hence, releasing the predator early in the beginning of growing season on low prey populations might be contributed toward maximizing the efficiency of pest control. The failure of coccinellids in controlling the mites at 


\section{Osman, M. A.}

higher population densities could be attributed to the low oviposition rate of predator at these densities, which reflects the desire to reduce intraguild competition and leads to lower chances of establishment of a viable colony of the predator at higher prey densities (Mandour, unpublished).

The results show that $S$. gilvifrons females increase predation rate as function of $T$. urticae larva densities. This fact, together with lower handling time for the coccinellid predator on prey larvae indicates that $S$. gilvifrons could be consumed high numbers of prey larvae per day. Therefore, the best time to release the predator in the field is being when the dominate prey population is larvae.

\section{Acknowledgements}

I would to thanks Prof Dr. S. A. Juliano (USA) and M. H. Bayoumy (Economic entomology Dept. for helping in statical analyses. Also, I thank Prof Dr. A. A. Osman (Economic entomology \& Agric. Zoology Dept.) Menofia University for helpful insights and critical reviews of the manuscript.

\section{REFERENCES}

Afshari, G. A. 1999. A survey on the ladybirds belong to genus Stethorus and study on the biology, prey consumption and population dynamics of Stethorus gilvifrons in sugarcane farms in Khuzestan, Iran. M.Sc. Thesis, Ahvaz, Iran

Ahmed, Z. I. and Ahmed, R.F., 1988. Biological studies of predator Stethorus gilvifrons Mulsant (Coleoptera: Coccinellidae) on the strawberry spider mite, Tetranychus turkestani Ugarov \& Nikolske (Acari: Tetranychidae). J. Bio. Sci. Res. 20, 22-23.

Alatawi, F. J.; Opit, G. P. ; Margolies, D. C. and Nechols, J. R. 2005. Within-Plant Distribution of Two-spotted Spider Mites (Acari: Tetranychidae) on Impatiens: Development of a Presence-Absence Sampling Plan. J. Econ. Entomol. 98: 1040-1047.

Allahyari, H.; Azmayeshfard, P. and Nozari , J. (2004). Effects of host on functional response of offspring in two populations of Trissolcus grandis on the sunn pest", J. of Appl. Entomol., 128: 39- 43.

Bailey, P. and Caon, G. 1986. Predation on twospotted mite, Tetranychus urticae Koch (Acarina: Tetranychidae) by Haplothrips victoriensis Bagnall (Thysanoptera: Phlaeothripidae) and Stethorus nigripes Kapur (Coleoptera: Coccinellidae) on seed lucerne crops in South Australia. Aust. J. Zool. 34: 515-525.

Bayoumy, M. H. ; Abdel-Kareim, A. I. ; Abdel-Salam, A. H. ; Abdel-Baky, N. F., and A. Schopf 2009. Host age preference and host searching efficiency of Encarsia citrina Craw. (Hymenoptera: Aphelinidae) a parasitoid of Euonymus scale, Unaspis euonymi Comstock (Hemiptera: Diaspididae) in Austria. $18^{\text {th }}$ International Entomological Conference, held in Göttingen, Germany, March 16-19.

Britto, E.P.J.; Gondim Jr. M.G.C. ; Torres, J.B. ; Fiaboe, K.K.M. ; Moraes, G.J and Knapp, M. 2009. Predation and reproductive output of the ladybird beetle Stethorus tridens preying on tomato red spider mite Tetranychus evansi. BioControl. doi:10.1007/s10526-008-9178-5. 
Chazeau, J.,1985. Predaceous insects. In: Helle,w., Sabelis, M.W. (Eds.),World Crop Pests, Spider Mites: Their Biology, Natural Enemies and Control. Elsevier Publication, Amsterdam, pp. 211-246.

Chazeau, J., 1974. Développement et fécondité de Stethorus madecassus Chazeau (Coléoptères, Coccinellidae) élev6 en conditions extérieures dans le sud-ouest de Madagascar. Cah. ORSTOM, Sér. Biol., 25: 27-33.

Coll, M. and Ridgway, R.L. 1995. Functional and numerical responses of Orius insidiosus (Heteroptera: Anthocoridae) to its prey in different vegetable crops. Ann. Entomol. Soc. Am. 88, 732-738.

Congdon, J. D.; Dunham, A. E. and van Loben Sels, R. C. 1993. Delayed sexual maturity and demographics of Blanding's Turtles (Emydoidea blandingii): implications for conservation and management of long-lived organisms. Conservation Biology 7:826-833.

De Clercq, P.; Mohaghegh, J. and Tirry, L. 2000. Effect of host plant on the functional response of the predator Podisus nigrispinus (Heteroptera: Pentatomidae). Biological Control 18, 65-70.

Eveleigh, E.S. and Chant, D.A. 1981. Experimental studies on acarine predator-prey interactions: effects of predator age and feeding history on prey consumption and the functional response (Acarina: Phytoseiidae). Can. J. Zool. 59: 13871406.

Fathipour, Y.; Hosseini, A.; Talebi, A. and Moharramipour, S. 2006. Functional response and mutual interference of Diaeretiella rapae (Hymenoptera: Aphidiidae) on Brevicoryne brassicae (Homoptera: Aphididae). Entomol. Fenn. 17, 90-97.

Fiaboe, K.K.M. ; Gondim, M.G.C. ; de Moraes, G.J. ; Ogol, C.K.P.O. and Knapp, M., 2007. Bionomics of the acarophagous ladybird beetle Stethorus tridens fed Tetranychus evansi. J. of Appl. Entomol. 131, 355-361.

Fleschncer, A. 1950. Studies on the searching capacity of the larvae of three predators of the citrus red mite. Hilgardia 20:233:265.

Gordon, R.D., 1985. The Coccinellidae (Coleoptera) of America north of Mexico. Journal of the New York Entomological Society 93, 654-678.

Haji-Zadeh, J. ; Kamali, G.K. and Assadi, H.B., 1993. Investigations on the functional response and populations fluctuations of Stethorus gilvifrons on red spider mite, Panonychus ulmi (Koch) in Karaj vicinity [Iran]. Applied Entomology and Phytopathology 61, 32-34

Gotoh, T., Nozawa, M. and Yamaguchi, K. 2004. Prey consumption and functional response of three acarophagous species to eggs of the two-spotted spider mite in the laboratory. Appl. Entomol. and Zool. 39, 97-105.

Hassell, M.P., 2000. The spatial and temporal dynamics of host parasitoid interactions. Oxford Series in Ecology and Evolution. Oxford University Press, London, UK, 198.

Holling, C.S., 1959. Some characteristics of simple types of predation and parasitism. Can. Entomol. 91, 385-398.

Holling, C.S., 1961. Principles of insect predation. Annl. Rev. Entomol., 6: 163-183

Holling, C. S., 1965. Functional response of predators to prey density and its role in mimicry and population regulation. Memoirs of Entomological Society of Canada 45: 3-60.

Houck, M.A., 1991. Time and resource partitioning in Stethorus punctum (Coleoptera: Coccinellidae). Environ. Entomol. 20, 494-497. 
Huffakerc, B.; Vand Evrie, M. and Mcmurtry, J. A. (1970). Eology of tetranychid mitesand their natural enemies: a review. 11. Tetranychid populations and their possible control by predators; an evaluation. Hilgardia 40: 391-458.

Hull, L. A., Asquith and Mowery, P. D, 1977. The functional response of stethorus punctum to densities of European red mite. Environ. Entomol., 6: 85 - 90.

Isikber, A.A., 2005. Functional response of two coccinellid predators, Scynus levaillanti and Cycloneda sanuinea, to the Cotton Aphid, Aphis gossypii. Turkish J. Agric. For., 29: 347-355

Juliano, S. A. 1993. Nonlinear curve fitting: predation and functional response curves. In: Scheiner, S.M., Gurevitch, J. (eds) Design and analysis of ecological experiments. Chapman and Hall, New York, pp 159-182

Juliano, S. A., 2001. Nonlinear curve fitting: predation and functional response curves. In: Design and Analysis of Ecological Experiments, 2nd edn. Ed. by Cheiner, S.M.; Gurven, J., New York: Chapman \& Hall, 159-182.

Mills, N. J., and Lacan, I. 2004. Ratio-dependence in the functional response of insect parasitoids: evidence from Trichogramma minutum foraging for eggs in small host patches. Ecol. Entom. 29: 208-216.

Mohaghegh, J.; De Clercq, P. and Tirry, L. 2001. Functional response of the predators Podisus maculiventris (say) and Podisus nigrispinus (Dallas) (Heteroptera: Pentatomidae) to the beet armyworm, Spodoptera exigua (Hubner) (Lepidoptera: Noctuidae): effect of temperature. J. Appl. Ent. 125, $131-134$.

Mori, K.; Nozawa, M. ; Arai, K. and Gotoh, T., 2005. Life-history traits of the acaraphagous lady beetle, Stethorus japonicus at three constant temperatures. BioControl 50: 35-51.

Munyaneza, J. and Obrycki, J. J. 1997. Functional response of Coleomegilla maculata (Coleoptera: Coccinellidae) to Colorado potato beetle eggs (Coleoptera: Chrysomelidae). Biological Control 8:215-224

Nwilene, F.E. and Nachman, G. 1996. Functional responses of Iphiseius degenerans and Neoseiulus teke (Acari: Phytoseiidae) to changes in the density of the cassava green mite, Mononychellus tanajoa (Acari: Tetranychidae). Exp. Appl. Acarol. 20:259-271.

Overmeer, W.P.J., 1985. Rearing and handling. In: Helle, W., Sabelis,

M.W. (Eds.), Spider Mites: Their biology, natural enemies and control. World Crop Pests. Elsevier

Roy, M., Brodeur, J. and Cloutier, C. 2003. Effect of temperature on intrinsic rates of natural increase $(\mathrm{rm})$ of a coccinellid and its spider mite prey. Bio Control 48, $57-72$

Sabelis, M.W., 1981. Biological control of two-spotted spider mites using phytoseiid predators. Part I: modelling the predator-prey interaction at the individual level. Agricultural Research Reports, Pudoc, Wageningen, p. 242.

SAS Institute, 2003. SAS/STAT user's guide. version 9.1 edition. SAS Institute Cary, NC.

Sohrabi, F. and Shishehbor, P. (2007). Functional and numerical responses of stethorus gilvifrons Muslant feeding on strawberry spider mite, Tetranychus turkestani Ugarov and Nikolski. Pakistan journal of biological science 10 (24): 4563-4566.

Sim, C., Seo, E. and Cho, K. (2003) Life table and sensitivity analysis as fitness evaluation method of fenpyroximate and pyridaben resistant twosoptted spider mite (Tetranychus urticae Koch). J. Asia-Pacific Entomol. 6: 193-199. 
Solomon, M. 1949. The natural control of animal populations. J. of Anim. Ecol. 41: 369-383.

Takafuji, A.; Ozawa, A.; Nemoto, H. and Gotoh, T. 2000. Spider mites of Japan: their biology and control. Exp. Appl. Acarol. 24: 319-335.

Tanigushi, L.K. and McMurtry, J.A., 1977. The dynamics of predation of Stethorus picipes (Coloptera: Coccinellidae) and Typhlodromus floridanus on the prey Oligonychus punicae (Acarina: Phytoseiidae, Tetranychidae). 1. Comparative life history and life table studies. Hilgardia 45, 237-261.

Trexler, J.C. ; Charles, E.M. and Travis, J. 1988. How can the functional response best be determined? Oecologia 76: 206-214.

Ullah, I., 2000. Aspects of the biology of the ladybird beetle Stethorus vegans (Blackburn) (Coleoptera: Coccinellidae). Doctoral thesis, Centre For Horticulture and Plant Sciences, University of Western Sydney, Hawkesbury, Richmond, NSW Australia, xvii +, 183 pp

Van Lenteren, J.C. and Bakker, K. 1976. Functional responses in invertebrates. Neth. J. Zool. 26:567-572.

Wang, J.J. and Tsai, J.H., 2001. Development and functional response of Coelophora inaequalis (Coleoptera: Coccinellidae) feeding on brown citrus aphid, Toxoptera citricida (Homoptera: Aphididae). Agric. For. Entomol. 3, 65.

Zhang, Z. -Q., 2003. Mites of greenhouse. Identification, biology and control. CABI Publishing. 244 pp.

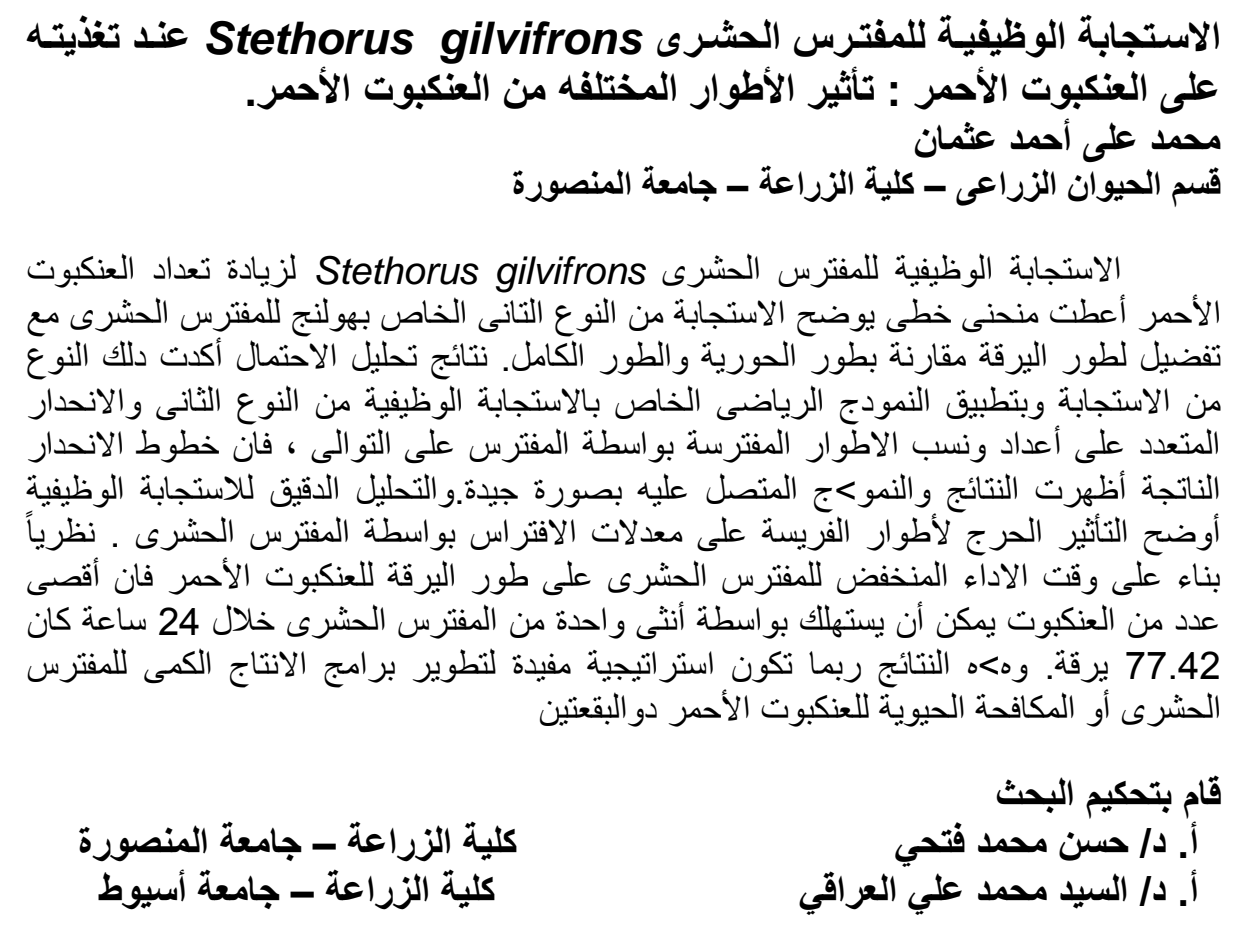

